ISSN 1414-6509

\title{
Saneamento básico e ampliações das liberdades substantivas
}

\author{
Joel de Jesus Macedo \\ Doutorando em Desenvolvimento Econômico pela Universidade Federal do Paraná (UFPR) \\ Endereço para contato: Rua Mateus Leme 1666 - Centro Cívico - Curitiba - PR \\ CEP: 80530-010 - E-mail: joelzmacedo@ gmail.com \\ Amanda Massaneira de Souza Schuntzemberger \\ Doutoranda em Desenvolvimento Econômico pela Universidade Federal do Paraná (UFPR) \\ Endereço para contato: Avenida Sete de Setembro, 4349 - Curitiba - PR \\ CEP: 80250-205 - E-mail: mandymss@gmail.com
}

Recebido em 23 de janeiro de 2016. Aceito em 29 de fevereiro de 2016.

\section{RESUMO}

Diante dos problemas decorrentes da escassez de água no mundo e atualmente assombrando os principais Estados brasileiros, cabe destacar que o saneamento é fundamental para as condições de saúde e produtividade das pessoas. O objetivo deste estudo é analisar se a disponibilidade do saneamento básico implica na redução do afastamento do trabalho. Para explicar o afastamento, selecionaram-se as variáveis: gênero, cor, idade, localização da residência, anos de estudo, acesso a água tratada e acesso a rede geral de esgoto. Para alcançar o objetivo do estudo, utilizou-se um modelo econométrico Logit. Verifica-se a influência direta das variáveis sexo dos indivíduos, idade e anos de estudo ao quadrado sobre o afastamento das atividades laborais. Por outro lado, constata-se que as variáveis acesso a água tratada, acesso a rede de esgoto, cor do indivíduo, anos de estudo, idade ao quadrado e situação censitária tem relação inversa ao afastamento do trabalho por ausência de saneamento básico.

Palavras chave: Liberdades Substantivas, Oportunidades Sociais, Efeitos do Saneamento sobre a Assiduidade do Trabalhador.

\begin{abstract}
Given the problems related to water scarcity in the world and which currently concern the major Brazilian states, it is worth noting that sanitation is critical to the health and productivity of people. This study aims to analyze the availability of sanitation implies the reduction of absence from work. In order to explain the absence from work, we selected the variables: gender, color, age, home location, years of schooling, access to treated water and access to the sewerage system. To achieve the goal, we used a logit econometric model. There is a direct influence of the variables gender of individuals, age and years of schooling squared on the absence from work activities. On the other hand, the variables access to treated water, sewerage system, color of the individual, years of schooling, age squared and situation in the census have an inverse relation to absence from work due to lack of sanitation.
\end{abstract}

Key-words: Substantial Freedoms, Social Opportunities, Effects of Sanitation on Attendance at Work.

RE\&D Econ. e Desenv., Santa Maria, vol. 27, n.2, p. 297 - 307, jul. - dez. 2015 


\section{INTRODUÇÃO}

Em termos globais, um grande número de pessoas continua sem acesso a abastecimento de água potável e saneamento. De acordo com dados compilados pela World Health Organization (WHO) e da Unicef, por meio do Programa Conjunto de Monitoramento do Abastecimento de Água e Saneamento (WHO; UNICEF, 2012), em 2010, 783 milhões de pessoas usavam fontes não apropriadas para suprir suas necessidades de água potável, e 2,5 bilhões de pessoas continuavam a utilizar uma instalação de saneamento não adequada ou defecavam a céu aberto.

Diante dos problemas decorrentes da escassez de água no mundo e atualmente assombrando os principais Estados brasileiros, cabe destacar que o saneamento é fundamental para as condições de saúde e produtividade das pessoas. Um trabalhador saudável é mais produtivo e, consequentemente, mais capacitado a auferir maior rendimento. Além disso, o saneamento é necessário tanto para a moradia quanto para as atividades econômicas.

Dados da Confederação Nacional de Indústria (CNI) evidenciam que cada R 1 bilhão investido em saneamento básico gera, nos setores de indústria, comércio e serviços, o equivalente a outros R \$ 3,1 bilhões. A CNI alerta, ainda, que investir em saneamento é investir em saúde e no desenvolvimento sustentável dos municípios, com geração de emprego e renda.

Diante do exposto, acredita-se que é relevante estudar o saneamento básico ou apresentar argumentos em defesa do investimento, estabelecendo correlação entre a disponibilidade do saneamento e a redução de problemas de saúde, e ainda apresentar os ganhos econômicos oriundos desses investimentos, uma vez que estes podem estar diretamente relacionados com o desenvolvimento econômico de uma nação.

Cabe notar que, na ótica de Sen (2000, p. 39), a perspectiva baseada na liberdade apresenta semelhança genérica com a preocupação comum com a "qualidade de vida", esta perspectiva também se concentra no modo como as pessoas vivem, e não apenas nos recursos que elas possuem.

No interesse de fomentar o debate, engajando interessados em um projeto de um Estado desenvolvido, justo e eficiente, este estudo pretende analisar os efeitos do saneamento sobre a saúde e o bem-estar. Mais especificamente, pretende analisar os efeitos da disponibilidade do saneamento básico implica na redução do o afastamento do trabalho.

Apesar de a grande parcela do setor já estar sob regulação, muitos investimentos não puderam ser colocados em prática, talvez, em virtude de muitos entraves antigos. No entanto, isso apenas fortalece a importância do engajamento da sociedade e de todos os níveis do governo. O presente estudo justifica-se pela importância do saneamento básico para que a população brasileira alcance um nível de desenvolvimento humano compatível com as potencialidades e as realizações do país.

Os efeitos do saneamento básico sobre o desenvolvimento econômico e humano são diversos, entre os quais se incluem os ganhos de produtividade das pessoas. Um trabalhador saudável produz mais; logo, aufere um rendimento maior. Além disso, o saneamento também qualifica o território tanto para a moradia quanto para as atividades econômicas.

A análise dos efeitos do saneamento sobre o afastamento do trabalho se deu a partir do cruzamento de informações das pessoas afastadas do trabalho por motivos de doenças como diarreia e vômito, de falta de acesso a água tratada e de baixos indicadores sociais e econômicos.

\section{REFERENCIAL TEÓRICO}

A Agência Nacional de Águas - ANA (2008), em nota técnica, destaca que o déficit sanitário no Brasil está associado aos altos índices de mortalidade, morbidade das doenças, afastamentos nos postos de trabalho, redução da vida útil dos cidadãos e não disponibilidade de água em qualidade e quantidade para o consumo humano. Nessa perspectiva, Eshevenguá (s.d.) aponta que as doenças associadas à falta de saneamento básico elevam os gastos do sistema de saúde nacional devido às frequentes internações hospitalares e ao uso excessivo de medicamentos. Em seus estudos, a autora destaca que, nos hospitais públicos brasileiros, $68 \%$ das internações são de pessoas acometidas por

RE\&D Econ. e Desenv., Santa Maria, vol. 27, n.2, p. 297 - 307, jul. - dez. 2015 
doenças adquiridas com água contaminada, e que o Ministério da Saúde gasta cerca de R\$250 milhões ao mês para tais atendimentos.

Muitas doenças de veiculação hídrica podem ser evitadas com o acesso a água tratada nos domicílios. Corroborando o exposto por Eshevenguá (s.d.), de acordo com a World Health Organization - WHO (2012), o governo brasileiro gasta US\$ 2,5 bilhões por ano no tratamento de pessoas portadoras de doenças relacionadas à falta de saneamento básico. O problema se agrava porque a maior parte do déficit de saneamento básico se concentra em áreas mais pobres e municípios de pequeno porte e distantes dos grandes centros urbanos. Nesses locais, o investimento nem sempre se apresenta economicamente viável (OLIVEIRA; CARRERA-FERNADEZ, 2004).

\subsection{Os efeitos do saneamento sobre a saúde}

A partir das informações do DataSUS (2009), verificou-se que foram registradas mais de 462 mil internações por infecções gastrintestinais em todo o país. Cerca de 206 mil foram classificadas pelos médicos como diarreia e gastrenterite de origem infecciosa presumível, e pouco mais de 10 mil casos, como shiguelose, amebíase ou cólera, e, ainda, 246 mil foram registrados como outras doenças infecciosas intestinais. Quanto à faixa etária, 251 mil internações eram de crianças e jovens até 14 anos, um grupo etário em que esse tipo de doença é particularmente mais perigoso.

Sen (2000, p. 29) destaca que um número imenso de pessoas em todo o mundo é vítima de várias formas de privação de liberdade. Entre os diversos fatores que privam a liberdade dos indivíduos, está a falta de saneamento básico ou a água tratada, que, com frequência leva as pessoas à morte prematura. O autor deixa implícito que o saneamento básico e o fornecimento de água tratada são uma das oportunidades sociais que podem servir de instrumento para o alcance da liberdade substantiva. Destaca que essa facilidade é importante no sentido de propiciar ao indivíduo viver uma vida saudável, livrando-se da morbidez evitável e da morte prematura.

\subsection{Liberdades e a qualidade de vida}

Sen (2000, p. 113) destaca que, quanto mais inclusivo for o alcance dos serviços de saúde, maior será a probabilidade de que mesmo os potencialmente pobres possam superar a penúria.

$\mathrm{O}$ acesso a bens e serviços básicos pode ser considerado desigual no país. Levando isso em consideração, este trabalho está fundamentado na ótica de Sen (2000), que considera o saneamento como um dos instrumentos de ampliação das liberdades sociais. O autor destaca que a ausência de alguns serviços básicos, incluindo o saneamento, nos primeiros anos de vida dificulta que o indivíduo desempenhe seu papel socioeconômico quando adulto. Essa desigualdade pode ser ainda maior nas áreas rurais, as quais são, por si, promotoras de desigualdade face às áreas urbanas. A população rural é, em geral, constituída por indivíduos de baixa renda, com padrões culturais distintos dos urbanos e, em sua maioria, com baixo poder de exercer sua cidadania. Aqueles que vivem em áreas rurais tendem a ter menos acesso a serviços de saúde, educação e infraestrutura.

$\mathrm{O}$ acesso a bens primários provê condições iniciais de igualdade de oportunidade ou de igualdade de capacidades, como premissa do desenvolvimento humano. A ideia de desigualdade não pode ser restrita à posse ou à falta de bens materiais, mas deve ser relacionada às capacidades que os indivíduos possuem para utilizar bens materiais para alcançar níveis de satisfação e bem-estar (SEN, 2000; KAGEYAMA; HOFFMANN, 2006).

A intuição básica das "teorias igualitaristas de oportunidades" é a de que as pessoas devem ser compensadas por certas desigualdades nas quotas de recursos de que dispõem para levar à risca planos de vida e realizar o que valorizam. A sociedade deve recompensar seus membros por desigualdades pelas quais estes não podem ser responsabilizados e que terminam causando "resultados pobres" (SEN, 2000). Assim, a abordagem baseada nas oportunidades defende que uma sociedade justa seria aquela em que há plena igualdade de acesso a bens e serviços básicos necessários para o desenvolvimento de cada indivíduo, e não aquela em que há igualdade de resultados.

Dill e Gonçalves (2012) estimaram a desigualdade de oportunidade e sua evolução para o Brasil entre 1999 e 2009 e verificaram que, nesse período, as oportunidades de acesso a escola,

Econ. e Desenv., Santa Maria, vol. 27, n.2, p. 297 - 307, jul. - dez. 2015 RE\&D 
energia, água e saneamento foram dispostas de forma mais equitativa entre a população brasileira, mas ainda não atingiram a universalização plena dos serviços.

\subsection{Desemprego e privação de capacidades}

O debate que sustenta a argumentação favorável ao investimento em saneamento remonta à ideia de que a universalização do saneamento reduz significativamente os efeitos negativos, já mencionados, à saúde do indivíduo. Os problemas de saúde dos trabalhadores, normalmente, não são aceitos pelo empregador, uma vez que este precisa de empregados dispostos e assíduos. Assim, é comum, ao sinal de impossibilidade laboral, a demissão ou o afastamento do empregado com incapacidade por outro que apresente melhores condições. Logo, é fácil constatar que o não investimento em saneamento provoca doenças que, consequentemente, podem resultar em demissão ou desemprego do trabalhador.

Conforme Sen (2000, p. 117), há provas de que o desemprego tem efeitos que vão além da perda de renda, como dano psicológico que resulta em perda de habilidade e autoconfiança, aumento de doenças e morbidez, perturbação das relações familiares e da vida social, intensificação da exclusão social, etc. Portanto, as consequências da ausência de saneamento adequado ultrapassam os problemas relacionados diretamente à saúde.

\subsection{Modelos de afastamento do trabalho}

A literatura econômica apresenta vários modelos que possibilitam a análise de problemas em que a variável dependente, - neste caso, o afastamento do trabalho - é discreta, qualitativa, limitada a modelos de escolha binária.

Seja a equação geral da regressão linear dada por:

$Y_{i}=\beta_{0}+X_{1 i} \beta_{1}+\cdots+X_{k i} \beta_{k}+e_{i}$

A equação (1) também pode ser reescrita:

$Y_{i}=X_{i} i \beta+e_{i}$

Em geral, o $Y_{i}$, em regressões, representa a variável dependente do modelo estatístico, podendo ser binária ou contínua. Para este estudo, a variável será binária, cujos valores são 1 ou 0 . Usualmente, o valor 1 é atribuído à presença de certo atributo na primeira observação, enquanto o valor 0 é atribuído à ausência do atributo. Logo, em determinada equação, seriam possíveis apenas dois valores: $Y_{i}=1$, quando o acontecimento, para algum indivíduo, for observado, e $Y_{i}=0$, quando o acontecimento não for observado.

Diante de problemas cuja variável dependente seja binária, é comum o uso dos modelos Probit e Logit, ou seja, quando a variável dependente assume 0 ou 1, especifica-se um modelo de resposta binária da seguinte forma:

Na presença de acontecimentos do evento, tem-se a probabilidade do evento dada por:

$P_{i}=\operatorname{Pr} o b\left(Y_{i}=1 \mid X_{1 i}, X_{2 i}, X_{3 i}, \ldots, X_{k i}\right)$

A probabilidade do não acontecimento do evento é dado por:

$1-P_{i}=\operatorname{Pr} o b\left(Y_{i}=0 \mid X_{1 i}, X_{2 i}, X_{3 i}, \ldots, X_{k i}\right)$

RE\&D Econ. e Desenv., Santa Maria, vol. 27, n.2, p. 297 - 307, jul. - dez. 2015 
A partir da das equações (3) e (4), o valor médio de $Y_{i}$ condicional é a $\left(X_{1 i}, X_{2 i}, X_{3 i}, \ldots, X_{k i}\right)$; caso exista, será:

$E\left(Y_{i}\right)=0\left(1-p_{i}\right)+1\left(p_{i}\right)=P_{i}$

Consequentemente, se na equação1 a $E\left(Y_{i}\right)=0$ então:

$E\left(Y_{i}\right)=\beta_{0}+x_{1 i} \beta_{1 i}++x_{2 i} \beta_{2 i} \ldots+x_{k i} \beta_{k i}=p_{i}$

Os modelos de probabilidade linear (MPL) são afetados por alguns problemas, como não normalidade de $\mu_{i}$, heterocedastidade de $\mu_{i}$, possibilidade de $\bar{Y}_{l}$ fora da faixa $0-1$ e valores de $R^{2}$ mais baixos. Apesar da possibilidade de correção dos problemas decorrente dos MPL, o seu uso ainda implica a pressuposição de que $P_{i}=E(Y=1 \mid X)$ aumenta linearmente com $\mathrm{X}$, ou seja, o efeito marginal de $X$ permanece constante o tempo todo. Portanto, na presença dessa problemática, faz-se necessário o uso de um modelo (probabilidade) que, dado os aumentos de $X_{\mathrm{i}}$, a $P_{i}=E(Y=1 \mid X)$, aumenta, mas nunca fora do intervalo $0-1$, e a relação entre $X_{i}$ e $P_{i}$ é não linear, ou seja, aproxima-se de zero a taxas cada vez menores quando $\mathrm{X}_{\mathrm{i}}$ fica menor, e aproxima-se de 1 a taxas cada vez menores à medida que $X_{\mathrm{i}}$ aumenta.

Para resolver o problema apontado no parágrafo anterior, a literatura econômica apresenta alguns modelos possuem as características necessárias, como o caso do modelo Logit. O modelo apresentado por Wooldridge (2010) considera $G$ uma função que assume estritamente valores entre zero e um, isto é, $0 \leq G(z) \leq 1$, para todos os números z reais. Isso garante que as probabilidades estimadas de respostas estejam estritamente entre zero e um.

Uma das funções não lineares para a função $G$ que fornecem as garantias de que as probabilidades estejam entre 0 e 1 é a função logística:

$G(z)=\frac{\exp ^{z}}{1+\exp ^{z}}$

O modelo Logit, que possui G como função logística, pode ser derivado de um modelo de variável latente. Seja $\mathrm{Y}^{*}$ uma variável não observada, ou latente, determinada por:

$$
\begin{aligned}
& Y^{*}=\beta_{0}+\beta_{1} X_{1}+\beta_{2} X_{2}+\cdots+\beta_{k} X_{k}+\varepsilon \\
& Y^{*}=\beta_{0}+\beta X+\varepsilon, \quad Y=1\left(Y^{*}>0\right)
\end{aligned}
$$

\section{METODOLOGIA}

Conforme já explorado no referencial teórico, as variáveis dependentes do modelo estatístico são binárias ou contínuas, e os valores são estritamente positivos. No entanto, é preciso considerar que muitos indivíduos podem ter se afastado do trabalho não por motivos de saúde decorrentes da ausência de saneamento, mas por outros motivos. Dessa forma, o uso de um MPL para estimar a probabilidade de afastamento do trabalho por doenças decorrente do saneamento provavelmente levaria a estimação de probabilidades negativas, ou seja, não respeitaria a hipótese de medida de probabilidade que varia de 0 a 1. Para eliminar esse problema, conforme apresentado na equação (8) e (9), adotou-se o modelo econométrico Logit. Para cumprir o objetivo principal deste estudo, que é verificar se o saneamento tem implicações sobre a assiduidade do trabalhador em suas atividades laborais, ou seja, se os afastamentos do trabalho por motivos de saúde estão relacionados à ausência de saneamento básico. Para a explicar o afastamento das atividades, utilizaram-se as seguintes variáveis:

Econ. e Desenv., Santa Maria, vol. 27, n.2, p. 297 - 307, jul. - dez. 2015 RE\&D 


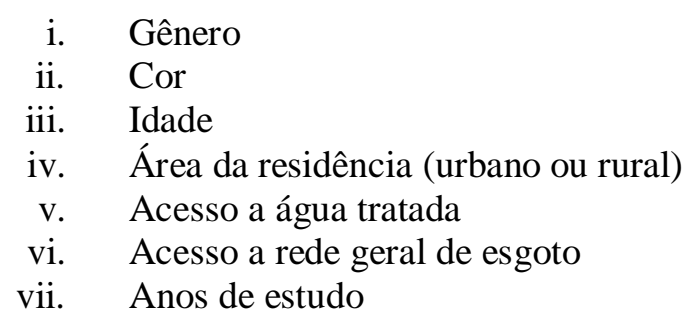

A partir dessas variáveis, adotou-se o seguinte modelo geral:

$$
A T_{i}=
$$

$\beta_{0}+\beta_{1}$ Gênero $_{i}+\beta_{2}$ Cor $_{i}+\beta_{3}$ Idade $_{i}+\beta_{4}$ Área da residencia $i+\beta_{5}$ Acesso a água tratada $_{i}+$ $\beta_{6}$ Acesso a rede geral de esgoto $_{i}+\beta_{7}$ Anos de estudo $o_{i}+\beta_{8}$ Idade $_{i}^{2}+$

$\beta_{9}$ Anos de estudo ${ }_{i}^{2}+\varepsilon_{i}$

Onde:

AT: (afastamento do trabalho): é uma variável dummy que assume o valor 1 caso o trabalhador tenha se afastado por problema decorrente de saneamento, e 0, em caso contrário;

Gênero: assume o valor 1 para o gênero masculino e 0 para o gênero feminino;

Cor: assume o valor 1 se o indivíduo for da cor branca e 0 em caso contrário;

Idade: medida em anos de vida;

Área da residência: Assume valor 1 se o imóvel se localizar na área urbana e 0 se for rural;

Acesso a água tratada: assume valor 1 se possuir acesso a água tratada e 0 em caso contrário;

Acesso a rede de esgoto: assume valor 1 se possuir acesso a rede de esgoto e 0 em caso contrário;

Anos de estudo: anos de educação formal

A especificação das variáveis seguiu abordagem semelhante à utilizada por Barros et al. (2008), ou seja: binária para gênero, acesso a água tratada e acesso a rede geral de esgoto; linear para a idade e educação do indivíduo; e quadrática para a idade e educação do indivíduo de referência. Mesmo com as especificações, as funções continuam lineares nos parâmetros. Para construir a variável dummy para raça, as cinco categorias apresentadas na PNAD 2008 foram englobadas em apenas duas: brancos e não brancos, conforme o critério estabelecido por Bourguignon et al. (2007). Assim, a primeira categoria inclui indivíduos brancos e amarelos, e a segunda, pretos, pardos e indígenas.

\begin{tabular}{|l|c|l|}
\hline \multicolumn{1}{|c|}{ Variável } & Denominação & \multicolumn{1}{c|}{ Especificação } \\
\hline Gênero & Sexo & Binária: 1 - Masculino 0 - Feminino \\
Cor & Cor & Binária: 1 - Branco 0 - Outros \\
Esgoto & Possui rede coletora de esgoto & Binária: 1 - Sim 0 - Não \\
Água & Possui água tratada & Binária: 1 - Urbano 0 - Rural \\
Anos de estudo & Estudo pessoa de referência & Binária: 1 - Sim 0 - Não \\
Área da residência & Urbano & Binária: 1 - Urbano 0 - Rural \\
Idade & Idade & Linear \\
Anos de estudo & Educação & Linear \\
Idade & Idade & Quadrática \\
Anos de estudo $^{2}$ & Educação & Quadrática \\
\hline
\end{tabular}

Quadro 1 - Especificação das variáveis

Fonte: Adaptado de Vega et al. (2010)

O Quadro 1 apresenta o descritivo das variáveis utilizadas, suas denominações e as respectivas especificações.

RE\&D Econ. e Desenv., Santa Maria, vol. 27, n.2, p. 297 - 307, jul. - dez. 2015 


\section{ANÁLISE DOS DADOS}

Os dados utilizados neste trabalho e que alimentam a regressão logística foram extraídos da Pesquisa Nacional de Amostras de Domicílios (PNAD, 2008), disponibilizada pelo IBGE. Como os dados são amostrais, cuidou-se para que fossem aplicados os respectivos pesos das amostras, possibilitando a expansão dos resultados para toda a população do país.

A Tabela 1 apresenta a distribuição dos indivíduos, a nível de Brasil, que foram afastados das atividades laborais por algum motivo de saúde que pode ou não estar relacionado a ausência de saneamento.

Tabela 1 - Distribuição por sexo

\begin{tabular}{lccc}
\hline Sexo & Frequência & Percentagem & Acumulado \\
\hline 0.000 & 96,084 & 63.990 & 63.990 \\
1.000 & 54,064 & 36.010 & 100.000 \\
\hline Total & $\mathbf{1 5 0 , 1 4 8}$ & $\mathbf{1 0 0 . 0 0 0}$ & \\
\hline
\end{tabular}

Fonte: Elaborado pelos autores a partir dos resultados da estimação

Dos 150.148 indivíduos investigados, 96.084 são do sexo feminino e 54.148 são do sexo masculino.

Para verificar o acesso ao serviço de saneamento básico, foram considerados tantos os domicílios que possuíam rede coletora de esgoto ou pluvial como aqueles que possuíam fossa séptica ligada à rede coletora de esgotos ou pluvial.

Tabela 2 - Acesso a esgotamento sanitário

\begin{tabular}{lccc}
\hline Esgoto & Frequência & Percentagem & Acumulado \\
\hline 0.000 & 83,288 & 55.470 & 55.470 \\
1.000 & 66,860 & 44.530 & 100.000 \\
\hline Total & $\mathbf{1 5 0 , 1 4 8}$ & $\mathbf{1 0 0 . 0 0 0}$ & \\
\hline
\end{tabular}

Fonte: Elaborado pelos autores a partir dos resultados da estimação

Do total de indivíduos verificados no ano de 2008 , verificou-se que apenas $44,5 \%$ possui acesso a esgoto, e a diferença 55,5\% ainda não possuía acesso a esgotamento sanitário.

Como acesso a água tratada, considerou-se os domicílios que possuem água encanada em, pelo menos, um cômodo do domicílio.

Tabela 3 - Acesso a água tratada

\begin{tabular}{lccc}
\hline Fonte Água & Frequência & Percentagem & Acumulado \\
\hline 0.000 & 38,430 & 25.590 & 25.590 \\
1.000 & 111,718 & 74.410 & 100.000 \\
\hline Total & $\mathbf{1 5 0 , 1 4 8}$ & $\mathbf{1 0 0 . 0 0 0}$ & \\
\hline
\end{tabular}

Fonte: Elaborado pelo autor a partir dos resultados da estimação

A Tabela 3 indica que, do total dos indivíduos verificados, $25.6 \%$ não possuem água tratada, e a diferença, $74,4 \%$, corresponde aos que possuem acesso a água tratada.

Quanto à idade, não foram apresentados os dados em formato de tabela em virtude da quantidade de observações, mas o intervalo da idade dos indivíduos ficou entre 10 a 108 anos, cuja maior frequência se deu aos 10 anos de idade, com frequência aproximada de 7\%, e no vigésimo ano a frequência caiu para $2 \%$, reduzindo ainda mais para os anos seguintes. Dessa forma, verifica-se que aproximadamente 55\% dos indivíduos têm idade entre 10 e 20 anos.

Quanto à raça dos indivíduos, seguindo o mesmo critério adotado no PNAD (2008) verifica-se que 66,453 são da cor branca, e 83,695 são de outras cores (preta, amarela, parda, indígena, ou sem declaração).

Econ. e Desenv., Santa Maria, vol. 27, n.2, p. 297 - 307, jul. - dez. 2015 RE\&D 
Tabela 4 - Cor

\begin{tabular}{lccc}
\hline Cor & Frequência & Percentagem & Acumulada \\
0.000 & 83,695 & 55.740 & 55.740 \\
\hline 1.000 & 66,453 & 44.260 & 100.000 \\
Total & $\mathbf{1 5 0 , 1 4 8}$ & $\mathbf{1 0 0 . 0 0 0}$ & \\
\hline Fonte: Elaborado pelo autor a partir dos resultados da estimação
\end{tabular}

Na Tabela 4, verifica-se que 44,26\% dos indivíduos são da cor branca, e todas as demais cores somaram juntos $55,74 \%$.

Quanto aos anos de estudo dos indivíduos, verifica-se que a maior parte dos indivíduos, $13,52 \%$, tem cinco anos de estudo; $13,18 \%$ possuem doze anos de estudo; e 12,7\% dos investigados têm um ano de estudo. Sendo os demais anos $\left(2^{\circ}\right.$ ao $4^{\circ}, 6^{\circ}$ ao $11^{\circ}$ e do $13^{\circ}$ ao $\left.17^{\circ}\right) 57 \%$ da população com frequência anual de estudo menor que $10 \%$.

Tabela 5 - Anos de estudo

\begin{tabular}{lccc}
\hline Anos estudo & Frequência & Percentagem & Acumulado \\
\hline 1.000 & 19,063 & 12.700 & 12.700 \\
2.000 & 4,654 & 3.100 & 15.800 \\
3.000 & 8,292 & 5.520 & 21.320 \\
4.000 & 12,443 & 8.290 & 29.610 \\
5.000 & 20,306 & 13.520 & 43.130 \\
6.000 & 13,327 & 8.880 & 52.010 \\
7.000 & 8,962 & 5.970 & 57.970 \\
8.000 & 8,532 & 5.680 & 63.660 \\
9.000 & 13,520 & 9.000 & 72.660 \\
10.000 & 6,539 & 4.360 & 77.020 \\
11.000 & 5,292 & 3.520 & 80.540 \\
12.000 & 19,792 & 13.180 & 93.720 \\
13.000 & 1,903 & 1.270 & 94.990 \\
14.000 & 1,244 & 0.830 & 95.820 \\
15.000 & 1,192 & 0.790 & 96.610 \\
16.000 & 4,597 & 3.060 & 99.670 \\
17.000 & 4,900 & 0.330 & 100.000 \\
\hline Total & $\mathbf{1 5 0 , 1 4 8}$ & $\mathbf{1 0 0 . 0 0 0}$ & \\
\hline
\end{tabular}

Fonte: Elaborado pelo autores a partir dos resultados da estimação

Quanto à situação censitária, o investigado pode residir na região urbana (cidade ou vila, área urbanizada ou não urbanizada), ou rural (aglomerado rural de extensão urbana, isolado, povoado, núcleo, outros).

\section{Tabela 6 - Situação censitária}

\begin{tabular}{lccc}
\hline Urbana & Frequência & Percentagem & Acumulada \\
\hline 0.000 & 21,065 & 14.030 & 14.030 \\
1.000 & 129,083 & 85.970 & 100.000 \\
\hline Total & $\mathbf{1 5 0 , 1 4 8}$ & $\mathbf{1 0 0 . 0 0 0}$ & \\
\hline Fonte: Elaborado pelos autores a partir dos resultados da estimação
\end{tabular}

A Tabela 6 indica que, do total dos indivíduos observados, aproximadamente $86 \%$ estão localizados na área urbana.

Tabela 7 - Motivo afastamento do trabalho

\begin{tabular}{llll}
\hline Motivo afastamento2 & Frequência & Percentagem & Acumulada
\end{tabular}

RE\&D Econ. e Desenv., Santa Maria, vol. 27, n.2, p. 297 - 307, jul. - dez. 2015 


\begin{tabular}{lccc}
0.000 & 142,664 & 95.020 & 95.020 \\
1.000 & 7,484 & 4.980 & 100.000 \\
Total & $\mathbf{1 5 0 , 1 4 8}$ & $\mathbf{1 0 0 . 0 0 0}$ & \\
\hline
\end{tabular}

Fonte: Elaborado pelos autores a partir dos resultados da estimação

A partir da Tabela 7, verifica-se que, do total de afastamentos do trabalho, a ausência de saneamento é responsável por aproximadamente $4,98 \%$.

\section{DESENVOLVIMENTO}

Com a equação definida na metodologia, pretende-se chegar a uma conclusão acerca da influência das variáveis abaixo citadas no nível de afastamento das atividades laborais, especificamente por ausência de saneamento ou por saneamento inadequado, para o ano de 2008.

Ao se levar em conta a estimação dos dados via modelo Logit, bem como o modelo econométrico já descrito, chegou-se aos resultados delineados a seguir, dos quais se procederá à devida análise crítica. Da primeira estimação, podem-se analisar resultados de modo a avaliarem os afastamentos do trabalho consequentes da ausência de saneamento básico, quando se tem as seguintes variáveis: sexo, acesso a rede de esgoto, acesso a água tratada, cor, situação censitária, anos de estudo e idade.

Logistic regression Number of obs. $=150.148 .000$

LR $\operatorname{chi} 2(7)=1.551 .150$

Prob $>$ chi $2=0.000$

Log likelihood $=-28,962.156$ Pseudo $R 2=0.126$

Tabela 8 - Resultado da Estimação

\begin{tabular}{lcccccc}
\hline Motivo afastamento2 & Coeficientes & Erro padrão & $\mathbf{z}$ & $\mathbf{P}>|\mathbf{z}|$ & Intervalo de confiança (95\%) \\
\hline Sexo & 0.039 & 0.025 & 1.530 & 0.126 & -0.011 & 0.089 \\
Esgoto & -0.137 & 0.029 & -4.680 & 0.000 & -0.194 & -0.079 \\
Fonte água & -0.355 & 0.090 & -3.940 & 0.000 & -0.532 & -0.179 \\
Cor & -0.008 & 0.004 & 1.840 & 0.065 & -0.000 & 0.016 \\
Idade & 0.043 & 0.002 & 18.000 & 0.000 & 0.038 & 0.048 \\
Anos estudo & -0.038 & 0.011 & -3.520 & 0.000 & -0.059 & -0.017 \\
Idade2 & -0.000 & 0.000 & -11.440 & 0.000 & -0.000 & -0.000 \\
Anosestudo2 & 0.000 & 0.001 & 0.120 & 0.107 & -0.001 & 0.001 \\
Situação censitária & -0.027 & 0.039 & 0.690 & 0.088 & -0.049 & 0.104 \\
cons & -3.776 & 0.061 & -61.580 & 0.000 & -3.897 & -3.656 \\
\hline
\end{tabular}

Fonte: Elaborado pelos autores a partir dos resultados da estimação

Para a efetiva análise, interpretação e conclusões, foram utilizados 150.148 (cento e cinquenta mil, cento e quarenta e oito) dados, todos extraídos do PNAD (2008), sendo necessário destacar ter o P estatístico trazido valores que indicam os coeficientes da estimação como estatisticamente significantes.

Como conclusão da análise, tem-se que, para a análise relativa ao sexo do trabalhador, conclui-se que o fato de ser o trabalhador do sexo masculino eleva as chances de ser afastado do trabalho por motivos decorrentes da ausência de saneamento. Não é o objetivo deste trabalho, e esse aspecto nem foi mensurado, mas é possível que o fato de os homens terem maior probabilidade de afastamento do trabalho esteja relacionado ao desempenho de atividades de maior risco ou à exposição à ausência de saneamento adequado.

Econ. e Desenv., Santa Maria, vol. 27, n.2, p. 297 - 307, jul. - dez. 2015 RE\&D 
A variável esgoto indica que o aumento da disponibilidade de acesso a rede de esgoto implica a redução da probabilidade de afastamento do trabalho por problemas decorrentes da ausência de saneamento.

A variável fonte de água demonstra que a ampliação da disponibilidade de água tratada reduz a probabilidade de afastamento do trabalho por problemas decorrentes da ausência de saneamento.

A variável cor indica que, se o indivíduo for da cor branca, tende a ter menor probabilidade de afastamento do trabalho. Esta característica pode estar relacionada à localização censitária do indivíduo. Ou seja, é possível que o indivíduo de cor branca habite em melhores condições do que indivíduos de cor não branca.

Para a variável idade, pode-se constatar que, quanto mais idoso for o trabalhador, menos chances ele terá de ser afastado de suas atividades laborais pela ausência de saneamento. Também não é objetivo deste trabalho discorrer sobre isso, mas acredita-se que tal resultado decorre, possivelmente, do grau de amadurecimento e conhecimento do indivíduo quanto aos principais riscos decorrente da ausência do saneamento, ou, então, da correta higiene pessoal.

A variável idade ao quadrado mede a magnitude da redução da chance de ser afastado do trabalho, dado o aumento da idade. Trata-se de uma análise que leva em conta a curva de progressão da idade comparativamente aos níveis de afastamento ocorridos nas idades iniciais.

Para a variável anos de estudo, pode-se observar que, quanto maior a educação do indivíduo, menor a probabilidade de ele ser afastado de suas atividades laborais por problemas decorrentes do saneamento básico.

Os anos de estudo ao quadrado demonstram a curva de evolução dos anos ao longo do tempo, no sentido de demonstrar que, a partir de determinado ponto de equilíbrio, passa a ser a citada relação entre a educação e o afastamento do trabalho por ausência de saneamento.

A variável situação censitária diz respeito à condição de os indivíduos residirem em área urbana ou rural. Os resultados da estimação demonstram que os indivíduos situados na região urbana têm menor probabilidade de afastamento de suas atividades laborais.

\section{CONSIDERAÇÕES FINAIS}

Adotando-se o modelo econométrico proposto, verifica-se a influência, direta das variáveis sexo dos indivíduos, idade e anos de estudo ao quadrado sobre o afastamento das atividades laborais. Por outro lado, constata-se que as variáveis acesso a água tratada, rede de esgoto, cor do indivíduo, anos de estudo, idade ao quadrado e situação censitária têm relação inversa ao afastamento do trabalho por ausência de saneamento.

Dessa forma, cumpre-se o objetivo deste estudo, que era verificar a influência do saneamento sobre a assiduidade do trabalhador. A partir da estimação, verificou-se que, entre outras variáveis, o acesso a água tratada e a rede coletora de esgoto implica a redução das chances de afastamento do trabalho. Por todo o exposto, verifica-se que a ampliação das liberdades substantivas pode estar associada à disponibilidade de acesso ao saneamento.

O presente estudo utilizou dados verificados em 2008; porém, recomenda-se a atualização da pesquisa diante de nova uma publicação da PNAD, uma vez que, em 5 de janeiro de 2007, foi promulgada a Lei n. 11.445, que previa reformas de modernização para o setor, cujos reflexos, acredita-se, ainda não foram verificados na PNAD 2008.

Acredita-se, ainda, que, nas últimas duas décadas, o Brasil tenha conseguido reduzir significativamente os níveis de pobreza. Esta conquista certifica que o país está no caminho do desenvolvimento e, portanto, está equacionando os problemas marcantes e recorrentes da sociedade brasileira, como educação deficitária ou insuficiente e desigualdade dos níveis na distribuição de renda. Contudo, no quesito saneamento, avançou-se pouco.

\section{REFERÊNCIAS}

RE\&D Econ. e Desenv., Santa Maria, vol. 27, n.2, p. 297 - 307, jul. - dez. 2015 
ANA. Agência Nacional de Águas. Saneamento básico. Disponível em: <http://www.ana.gov.br/pnrh/DOCUMENTOS/5Textos/6-1Saneamento4_04_03.pdf >. Acesso em: 05 nov. 2015.

BARROS, R. P.; VEGA, J. M.; CHANDUVI, J. S. Measuring inequality of opportunities for children. Washington, DC: World Bank, 2008.

BOURGUIGNON, F.; FERREIRA, F. H. G.; MENÉNDEZ, M. Inequality of opportunity in Brazil. Review of Income and Wealth, Series 53, n. 4, p. 585-618, dez. 2007.

BRASIL. Instituto Brasileiro de Geografia e Estatística (IBGE). Pesquisa Nacional por Amostra de Domicílios. Rio de Janeiro: IBGE; 2008. [2010 out 13]. Disponível em: http://www.ibge.gov.br/home/estatistica/populacao/panorama_saude_brasil_2003_2008/qstpnadsa ude2008.pdf. Acesso em: 09 nov.2015

DATASUS. Departamento de Informática do SUS. Informações de Saúde (TABNET). Dados de 2009. Brasília: Ministério da Saúde. Disponível em: 〈http://datasus.saude.gov.br/informacoes-desaude/tabnet>. Acesso em: 15 nov. 2014.

DILL, H. C.; GONÇALVES, F. O. Igualdade de oportunidade no Brasil entre 1999 e 2009: estimação e decomposição através do valor de Shapley. PPE, Rio de Janeiro, v. 42, n. 2, p. 185-210, ago. 2012.

ESHEVENGUÁ, Ana. Brasil. s.d. Disponível em:

<http://www.ecoeacao.com.br/index.php?option=com_content\&task=view\&id=371\&Itemid=39>. Acesso em: 10 nov. 2014.

KAGEYAMA, A.; HOFFMANN, R. Pobreza no Brasil: uma perspectiva multidimensional. Economia e Sociedade, Campinas, v. 15, n. 10, p.79-112, 2006.

OLIVEIRA, A.; CARRERA-FERNADEZ, J. Análise da eficiência do setor de saneamento básico no Brasil. In: ENCONTRO REGIONAL DE ECONOMIA DA ANPEC - FÓRUM BANCO DO NORDESTE DE DESENVOLVIMENTO, 9, 2004. Fortaleza. Anais... Fortaleza, 2004.

SEN, A. Desenvolvimento como liberdade. São Paulo: Companhia das Letras, 2000.

VEGA, J. R. M.; BARROS, R. P. de; SAAVEDRA, J.; GIUGALE, M. Do our children have a chance? The 2010 Human Opportunity Report for Latin America and the Caribbean. World Bank, Washington, DC, 2010. 176 p.

WHO. World Health Organization; UNICEF. United Nations Children's Fund. Progress on drinkingwater and sanitation: 2012 update. Report of the WHO/UNICEF Joint Monitoring Programme on Water Supply and Sanitation. New York; Geneva: WHO; UNICEF, 2012.

WOOLDRIDGE, J. M. Introdução à econometria uma abordagem moderna. 4. ed. São Paulo: Cengage Learning, 2010.

Econ. e Desenv., Santa Maria, vol. 27, n.2, p. 297 - 307, jul. - dez. 2015 RE\&D 